\author{
Research Article
}

\title{
Boesenbergia rotunda Ethanolic Extract Inhibits Compound Action Potentials via Opioid Receptors
}

\author{
Banulata Gopalsamy ${ }^{1}$, Jasmine Siew Min Chia ${ }^{1}$, Farihah Hanani Ghazali ${ }^{1}$, Ammar Izzati Amir Ramadan ${ }^{1}$, \\ Wong Siong Jun ${ }^{1}$, Ahmad Akira Omar Farouk ${ }^{1}$, Mohd Roslan Sulaiman ${ }^{1}$, Mohd Khairi Hussain ${ }^{1}$ and Enoch \\ Kumar Perimal ${ }^{1, *}$ \\ ${ }^{1}$ Department of Biomedical Science, Faculty of Medicine and Health Sciences, Universiti Putra Malaysia, 43400 UPM Serdang, Selangor Darul Ehsan, \\ Malaysia.
}

https://doi.org/10.28916/lsmb.2.2.2018.15

Received 17 May 2018, Revisions received 9 July 2018, Accepted 9 July 2018, Available online 10 July 2018

\begin{abstract}
Boesenbergia rotunda, traditionally used to relieve stomach, abdomen, joint, muscle, and rheumatic pain was also reported for its antinociceptive effect on a mouse model. However, the possible pain relief effect of Boesenbergia rotunda ethanolic extract (BREE) via the inhibition to the neural pain pathway remains to be elucidated. This study investigated the inhibitory effect of BREE on compound action potentials (CAPs) and the possible involvement of the opioid receptors. The changes in the CAPs amplitudes of the frog's sciatic nerves were evaluated following the exposure to three different dosages of BREE $(1,3$ and $10 \mathrm{mg} / \mathrm{ml}$ and morphine $(3 \mathrm{mg} / \mathrm{ml})$. In another set of experiment, the nerves were pretreated with a non-selective opioid receptor antagonist, naloxone $(0.1 \mathrm{mg} / \mathrm{ml})$, before exposing the nerve to BREE $(1 \mathrm{mg} / \mathrm{ml})$ to investigate the involvement of opioid receptors in the CAPs inhibitory mechanism. The outcome showed a reduction in the CAPs amplitudes when treated with BREE $(1,3$ and $10 \mathrm{mg} / \mathrm{ml})$ whereby the effect was reversible. The CAPs inhibition by BREE was absent when the opioid receptors were blocked. Taken together, these findings suggest that BREE-induced CAPs amplitude reduction involves the activation of opioid receptors.
\end{abstract}

Keywords: Boesenbergia rotunda; compound action potential; opioid receptors; frog sciatic nerve

\section{Introduction}

Boesenbergia rotunda (L.) Mansf, a herbal plant that grows wildly in teak forests, is commonly used as traditional medicine in the Southeast regions of Asia (Chahyadi et al., 2014). This plant, formerly identified as Boesenbergia pandurata, is known as "Temu kunci" among Malays, "Krachai-Dang" among Thais and is recognized as finger root in English. Besides being used as a culinary herb, this plant has also been exploited for its vast medicinal properties. It is known to relief stomach, abdomen, joint, muscle and rheumatic pain (Eng-Chong et al., 2012). Extract of B. rotunda has been used by Indonesians as topical medicine, which acts like a local anaesthetic, treating body parts affected with rheumatism (Winarti and Wantiyah, 2015).

In addition to this, the antinociceptive and analgesic (Winarti and Wantiyah, 2015), antifungal and antiparasitic (Chuakul and Boonpleng, 2003), anti-inflammatory (Riswan and Sangat-Roemantyo, 2002), antioxidant (Shindo K, 2006) and anticancer (Kirana et al., 2003) properties of $B$. rotund $a$ has been well-documented. A few active compounds, specifically (-)-panduratin A (Tuntiwachwuttikul et al., 1984), 2',6'-dihydroxy-4'-methoxychalcone (Kurkin et al., 1990), 2',4'-dihydorxy-6'-methoxychalcone (Katerere et al., 2004) and (-)-4hydroxypanduratin A (Trakoontivakorn et al., 2001) isolated from the rhizomes of $B$. rotunda are known to exert neuroprotective effects (Shindo K, 2006).

B. rotunda also contains more than 51 flavonoid compounds that have been identified to date (Chahyadi et al., 2014). Most of the flavonoid's main skeletons are integrated with prenyl substituents (Win et al., 2008). Its strong biological activities might be attributed to these prenylated flavonoids since they are able to traverse the blood brain barrier (Youdim et al., 2004). In addition, Pinocembrin (5,7dihydroxyflavanone), another flavonoid isolated from the rhizomes of $B$. rotunda has been reported for its neuroprotective and antiexcitotoxic effects (Guang and Du, 2006; Shi et al., 2011). Its role in improving the neuronal survival rates and cognition as well as lowering the incidence of cortical neuronal damage and cell injury provides substantial evidence that $B$. rotunda closely interacts with the nervous system to elicit some of its properties.

\footnotetext{
* Correspondence: Department of Biomedical Science, Faculty of Medicine and Health Sciences, Universiti Putra Malaysia, 43400 UPM Serdang, Selangor Darul Ehsan, Malaysia.

e-Mail: enoch@upm.edu.my
}

(C) 2018 by the Author(s). Life Sciences, Medicine and Biomedicine (ISSN: 2600-7207) Published by Biome Journals. Wholly owned by Biome Scientia Sdn Bhd., previously by WWH Networks Sdn Bhd. Attribution-ShareAlike 4.0 International (CC BY-SA 4.0). This open access article is distributed based on the terms and conditions of the Creative Commons Attribution license https://creativecommons.org/licenses/by-sa/4.0/ 
The changes in the electrical membrane potential where it rapidly rises and falls, also known as action potential, is essential for transmission and encoding of information (Fry and Jabr, 2010). When a neuron receives an impulse, it is passed on to the next neuron ensuring the continuity of the impulse along its path. The sum of action potentials produced by each nerve fiber inside the nerve is called compound action potentials (CAPs). To investigate the analgesic action of $B$. rotunda, information on the direct influence of this extract on the neural pathway is essential. Other currently available drugs also uses similar mechanism where pain is alleviated by the inhibition of action potential conduction (Tremont-Lukats et al., 2005).

In this study we provided direct evidence on the effect of the $B$. rotunda ethanolic extract (BREE), on the inhibition of CAPs amplitude to support earlier claims that BREE is a potent analgesic and anesthetic. Further, the study explored the possible involvement of opioid receptors on the inhibitory mechanism of BREE on CAPs.

\section{Materials and methods}

Animals

This study was conducted in accordance with Universiti Putra Malaysia policy and code of practice for the care and use of animals for scientific purposes. All experimental procedures were carried out only after the approval from the Institutional Animal Care and Use Committee (Reference number: UPM/IACUC/AUP-U001/2017) was obtained. Frogs of the Rana catesbeiana species that weighed 200-300 $\mathrm{g}$ were used in this experiment. The frogs were housed in an aquarium $(50 \mathrm{x} 40 \mathrm{x} 40 \mathrm{~cm})$ with $2 \mathrm{~cm}$ of water at $20-24^{\circ} \mathrm{C}$ on a $12 \mathrm{~h}$ photoperiod. The animals were kept at the animal house of Faculty of Medicine and Health Sciences, Universiti Putra Malaysia to allow acclimatization for at least three days prior to experiments.

\subsection{Drugs and chemicals}

Tween 20, morphine sulphate and naloxone hydroxide were purchased from Sigma-Aldrich Chemical Co. (St. Louis, MO, USA). Morphine and naloxone were dissolved in $0.9 \%$ normal saline. Ringer's solution $\left(\mathrm{NaCl}, 118.87 \mathrm{mM} ; \mathrm{KCl}, 2.47 \mathrm{mM} ; \mathrm{CaCl}_{2}, 1.08 \mathrm{mM} ; \mathrm{NaHCO}_{3}\right.$, $2.38 \mathrm{mM} ; \mathrm{pH} 7.2$ ) was used as a temporary medium to keep the sciatic nerve before CAPs measurement procedure.

\section{Preparation of plant extract}

Fresh rhizomes of $B$. rotunda were purchased from the local market located in Kulim, Malaysia. The plant was identified by Mr. Shamsul Khamis, a resident botanist from Universiti Putra Malaysia (UPM), Serdang, Selangor, Malaysia. A sample of the specimen (Voucher number: SK 1780/10) was deposited at the Herbarium of Institute of Bioscience, UPM.

The extract was prepared by first tap washing the rhizomes, before they were sliced into small pieces and shade-dried. Then, the dried rhizomes were finally powdered using a commercial electrical blender. The fine powder was soaked in $95 \%$ ethanol at a ratio of $1: 10$ for three days at room temperature. The mixture was then filtered using a fine muslin cloth followed by filter paper. Next, the mixture was distilled under reduced pressure using Eyela rotary evaporator Tokyo Rikakikai Co., LTD, Japan). The extract was dried in an incubator at $40^{\circ} \mathrm{C}$ and stored at $4{ }^{\circ} \mathrm{C}$ until further usage. BREE was dissolved in Tween 20 and normal saline at a ratio of 5:95 and was prepared freshly just before use. Animals in the vehicle group received only Tween 20 and normal saline at a ratio of 5:95.

\subsection{Preparation of frog sciatic nerve}

The isolation and preparation of frog sciatic nerve was as previously described by Katsuki et al. (2006). In brief, the frogs were pithed using a sharp probe through the base of the frog's skull until a brief twitch was observed. Then, the spinal cord was severed until the frog's legs become completely limp. The frog is confirmed to be insensitive to pain when there was an absence of withdrawal reflex following toe pinch. Thereafter, both the left and right sciatic nerves were dissected from the lumbar plexus to the knee. Throughout the dissection procedure, the nerve was continuously moistened with Ringer's solution. The isolated sciatic nerves were placed in Ringer's solution until the following procedure. All experiments were carried out at room temperature, $20-24{ }^{\circ} \mathrm{C}$.

\section{Electrophysiological techniques}

CAPs of the frog's sciatic nerves were recorded using an extracellular recording technique with a PowerLab data acquisition system (ADInstruments, Inc., Colorado Springs, CO, USA). Approximately, $4.5 \mathrm{~cm}$ of the nerve segment was placed in a nerve chamber containing one pair of stimulating electrodes and two pairs of recording electrodes. The space between the electrodes was ensured to be the same throughout the entire procedure. Prior to the beginning of the experiment, we determined the stimulating voltage by testing CAPs recording beginning from $10 \mathrm{mV}$ up to $200 \mathrm{mV}$. Upon confirming that the stimulating voltage of $200 \mathrm{mV}$ was able to give the most stable recording, this value was maintained throughout the entire experiment.

2.6

Experimental design

Inhibitory Effects of BREE on CAPs

A total of 30 sciatic nerves were divided into five groups ( $n=6$ nerves per group $)$ as follows:

Group I : Vehicle (5\% Tween $20+95 \%$ normal saline)

Group II : BREE $1 \mathrm{mg} / \mathrm{ml}$

Group III : BREE $3 \mathrm{mg} / \mathrm{ml}$

Group IV : BREE $10 \mathrm{mg} / \mathrm{ml}$

Group V : Morphine $3 \mathrm{mg} / \mathrm{ml}$

As outlined in Figure 1, the nerves were soaked in their respective treatments for a total of 30 min where CAPs recordings were obtained at an interval of $5 \mathrm{~min}$. Nerves were then subjected to washing where they were soaked in Ringer's solution for 30 min. Again, CAPs 
amplitudes were recorded every 5 min throughout the washing step. The optimum values from these treatments were calculated and used in the following experiment.

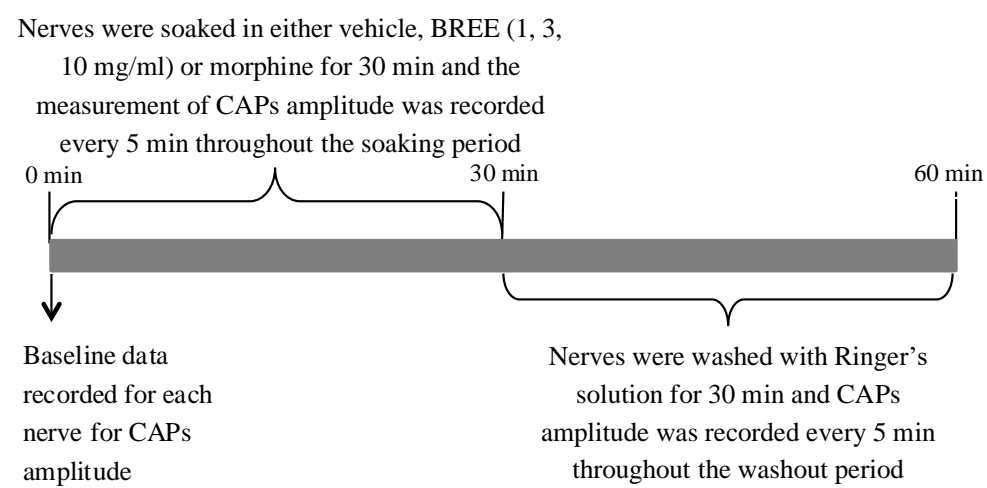

Figure 1: Timeline of CAPs recordings throughout the exposure to treatments $(1,3,10 \mathrm{mg} / \mathrm{ml}$ BREE and morphine $(3 \mathrm{mg} / \mathrm{ml})$ and wash out procedure.

Involvement of Opioid Receptors

A total of 18 sciatic nerves were allocated into three groups ( $n=6$ nerves per group) as follows:

Group I : Vehicle (5\% Tween $20+95 \%$ normal saline)

Group II : Naloxone hydrochloride $0.1 \mathrm{mg} / \mathrm{ml}$

Group III : Naloxone hydrochloride $0.1 \mathrm{mg} / \mathrm{ml}+$ BREE $1 \mathrm{mg} / \mathrm{ml}$

As outlined in Figure 2, the involvement of opioid receptors in the action potential inhibitory effect of BREE was evaluated by pretreating the nerves with Naloxone hydrochloride $(0.1 \mathrm{mg} / \mathrm{ml})$, a non-selective opioid receptor antagonist for $20 \mathrm{~min}$. Then, the nerves were exposed to BREE $(1 \mathrm{mg} / \mathrm{kg}$ ) for $30 \mathrm{~min}$. In groups of Vehicle and Naloxone Hydrochloride treatments, CAPS were taken during soaking for $30 \mathrm{~min}$. Nerves were washed by soaking in Ringer's solution for another $30 \mathrm{~min}$. Throughout the entire length of these procedures, CAPs amplitudes were recorded at a 5 min interval.

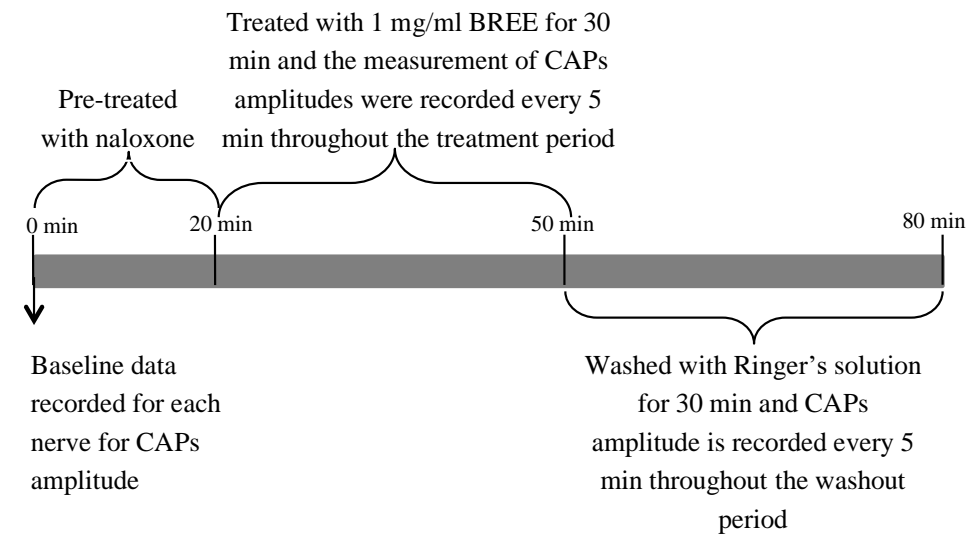

Figure 2: Timeline of CAPs recordings of nerve pre-treatment with naloxone hydochloride $(0.1 \mathrm{mg} / \mathrm{ml})$, BREE $(1 \mathrm{mg} / \mathrm{ml})$ and washout procedure.

\section{Statistical analysis}

The mean of individual CAPs amplitudes recorded under stable conditions at the start of the experiment was considered as baseline, and the amplitudes obtained after BREE was applied were expressed as percentage of the baseline to characterize the effects of BREE on nerve conduction ability. Data are expressed as mean \pm SEM. Data were analysed using GraphPad Prism Version 5.0 software (GraphPad San Diego, CA). Data were analyzed using two-way ANOVA followed by Bonferroni's post hoc analysis. A confidence interval of 5\% or less was considered to be statistically significant. In all cases, $\mathrm{n}$ refers to the number of sciatic nerves studied.

\section{Results}

3.1 Boesenbergia rotunda ethanolic extract (BREE) decreased the CAPs amplitude of frog sciatic nerves

The inhibitory effect of BREE on the CAPs recorded from the frog sciatic nerves was observed when the peak amplitude of CAPs gradually reduced as shown in Figure 3(A). Figure 3(B) demonstrates the average time course for changes in CAPs peak amplitudes following soaking into BREE (1 mg/ml), in comparison to its baseline level (at $0 \mathrm{~min}$ ). The $1 \mathrm{mg} / \mathrm{ml} \mathrm{BREE-induced} \mathrm{reduction} \mathrm{in} \mathrm{CAPs} \mathrm{peak} \mathrm{amplitude}$ 
attained an almost maximal inhibitory effect at $30 \mathrm{~min}$ of the soaking, where the average peak amplitude of the CAPs was $13.037 \pm 1.204 \mathrm{mV}$. In nerves treated with BREE $(1 \mathrm{mg} / \mathrm{ml})$ the CAP peak amplitude recovered to $99.8 \%$ of baseline level upon returning to the drug-free Ringer's solution during the washout period of $30 \mathrm{~min}$.

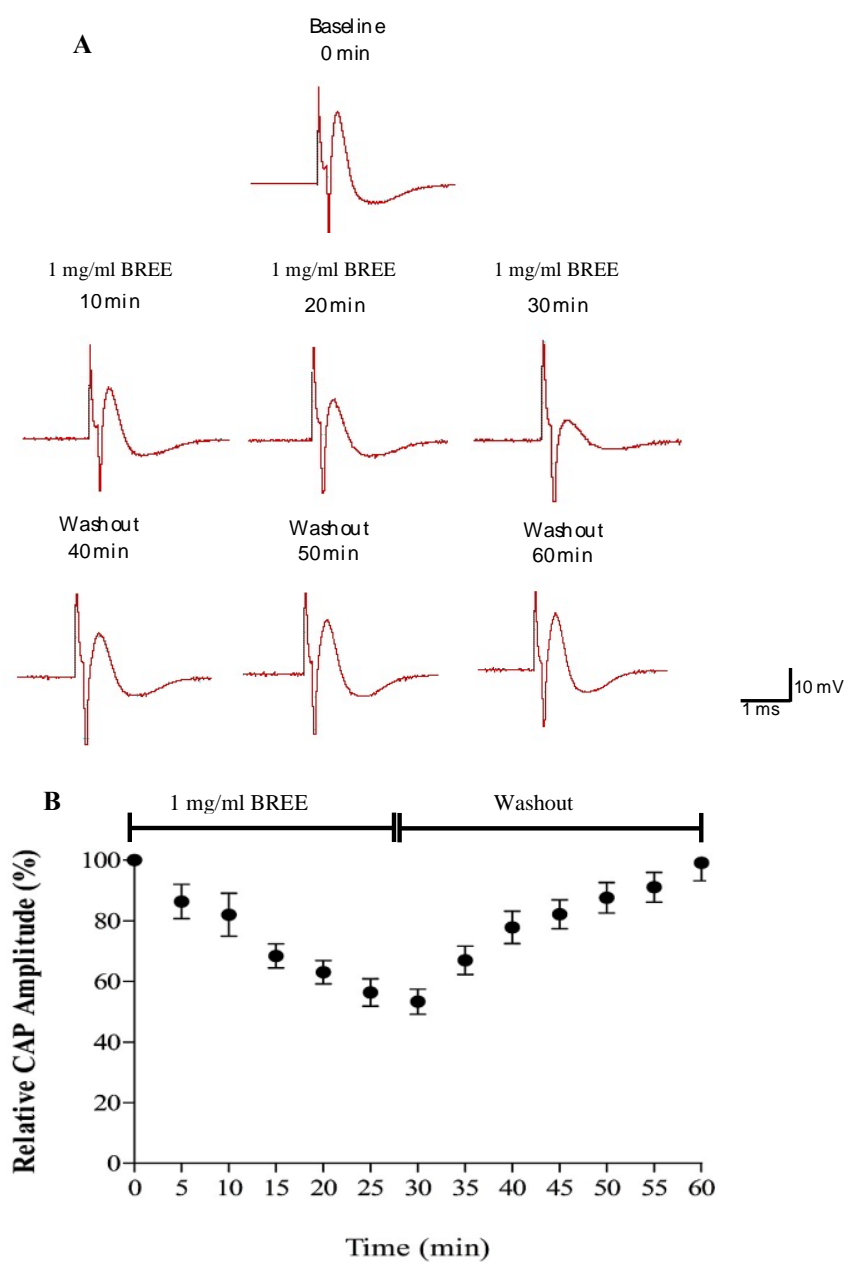

Figure 3: (A) Recording of CAPs before treatment at $0 \mathrm{~min}$, after exposure to BREE $(1 \mathrm{mg} / \mathrm{mL})$ at 10,20 and 30 min and thereafter at 40 , 50 and 60 min of washout. (B) Average time course of changes in CAP peak amplitudes following exposure to BREE (1 mg/ml) for $30 \mathrm{~min}$, relative to baseline. Results are shown as mean values \pm S.E.M; $n=6$ nerves per group.

The time course changes in CAP peak amplitude with an increase in time after soaking the sciatic nerve into vehicle, BREE at concentrations 1,3 and $10 \mathrm{mg} / \mathrm{ml}$ and morphine $(3 \mathrm{mg} / \mathrm{ml})$ are as shown in Figure 4 . As the concentrations of BREE increased, a significant reduction in the CAP amplitude was attained at a faster rate. BREE at a concentration of $1 \mathrm{mg} / \mathrm{ml}$ significantly $(\mathrm{p}<0.05$ ) reduced the CAPs amplitude at $30 \mathrm{~min}$ when compared to the control group. However, following an exposure to BREE at $3 \mathrm{mg} / \mathrm{ml}$, the CAPs amplitudes significantly $(\mathrm{p}<0.05)$ reduced from the control group at $20 \mathrm{~min}, 25 \mathrm{~min}$ and $30 \mathrm{~min}$. BREE at $10 \mathrm{mg} / \mathrm{ml}$ significantly reduced the CAPs amplitude at $15 \mathrm{~min}(\mathrm{p}<0.05)$ and further showed a significant $(\mathrm{p}<0.05)$ reduction as early as 20 min of exposure to the treatment, when compared with control group. It is noteworthy that, BREE $(10 \mathrm{mg} / \mathrm{ml})$ showed better CAP inhibition than morphine throughout the entire length of the procedure.

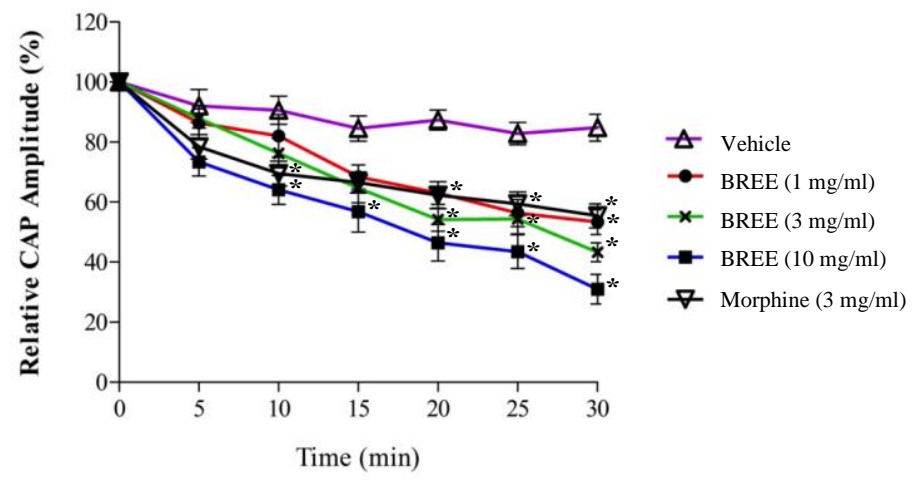

Figure 4: Comparison in average time course among CAP peak amplitude produced by vehicle, BREE (1, 3, $10 \mathrm{mg} / \mathrm{ml})$ and morphine at 3 $\mathrm{mg} / \mathrm{ml}$. Results are shown as mean values \pm S.E.M; $\mathrm{n}=6$ nerves per group. ${ }^{*} \mathrm{p}<0.05$ indicating significance as compared to vehicle. 
To investigate whether the BREE-induced reduction of CAPs amplitude is mediated by opioid receptors, the nerves were pre-treated with non-specific opioid receptor antagonist, naloxone $(0.1 \mathrm{mg} / \mathrm{ml})$ before exposing the nerves to BREE $(1 \mathrm{mg} / \mathrm{ml})$. The reduction in the CAPs amplitude caused by BREE was absent. This indicates that the action of BREE on CAPs amplitude was reversed by pre-treatment of the nonspecific opioid receptor antagonist as shown in Figure 5.

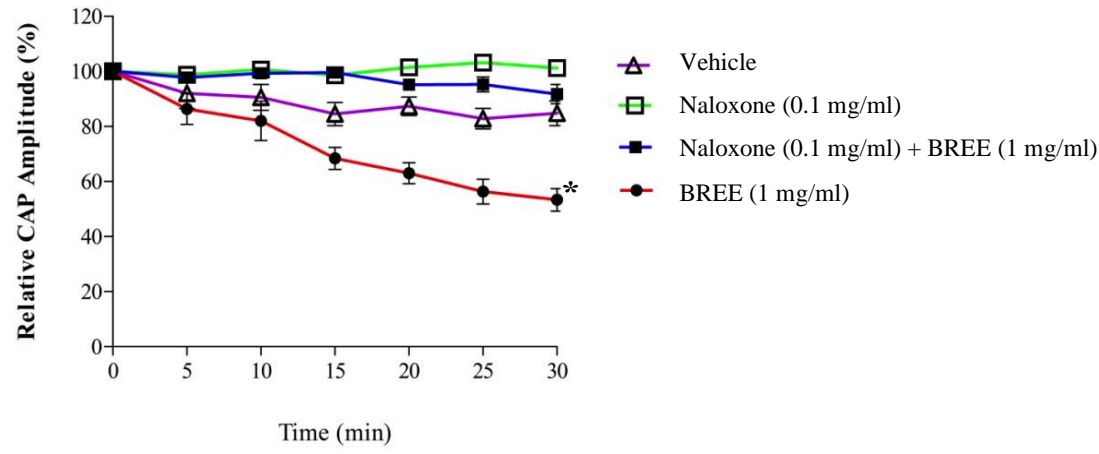

Figure 6: Effect of pre-treatment of naloxone $(0.1 \mathrm{mg} / \mathrm{ml})$ with BREE $(1 \mathrm{mg} / \mathrm{ml})$ on the CAPs amplitude of frog sciatic nerve during $30 \mathrm{~min}$ of exposure to BREE. Results are shown as mean values \pm S.E.M; $n=6$ nerves per group. $* \mathrm{p}<0.05$ indicating significance as compared to vehicle.

\section{Discussion}

Even though substantial evidence on the effect of BREE in alleviating pain is present, the direct involvement of BREE on the pathway that transmits pain has not yet been elucidated. Therefore, the crude extract of BREE serves as a preliminary screening against its effects towards compound action potential. This study further addressed the mechanism of action of $B$. rotunda by investigating the involvement of opioid receptors.

From the outcome, we observed a decrease in CAPs amplitude in frog sciatic nerves following treatment with BREE. This indicates that BREE modulates the propagation of action potential following nerve stimulation. The generation of action potential following a stimulus involves the opening and closing of various ion channels, particularly the $\mathrm{K}^{+}$and $\mathrm{Na}^{+}$ion channels, which are abundantly present across the neuronal lipid bilayers (Scholz, 2002). Similar observations have been reported in other opioids such as morphine, codeine, dihydrocodeine and ethylmorphine whereby their actions are known to be mediated via activation of TTX-sensitive voltage gated $\mathrm{Na}^{+}$channels and voltage gated $\mathrm{K}^{+}$channels (Mizuta et al., 2008).

Neurons are able to control ion fluxes through these channels, which is an essential process for the reception, conduction and transmission of signals. Generally, a decrease in CAPs amplitude has a direct relationship with the reduction of nerve conduction abilities (Li et al., 2010) which has significant effects in the biological system. Thus, the CAPs amplitude relies on the influx and efflux of Na+ and $\mathrm{K}+$ ions, altering the baseline resting potential level (Pandey and Deshpande, 2012). Nerve conduction are used as an indicator to identify nerve activity in signal conduction (Yao et al., 2015) which is important to regulate physical performance, including motor system physiological and pathological processes (Colucci et al., 2009; Chipman et al., 2014). In the peripheral nervous system, decreased neural activity usually indicates a decreased local response or lowered sensitivity to external stimulation. This further leads to reduced local metabolic rate demonstrating analgesia (Colucci et al., 2009; Li et al., 2010). Most importantly, the inhibitory action of BREE was reversible as the recorded amplitudes were restored to their initial values following the withdrawal of the treatments. To the best of our knowledge there are no reports on the involvements of $B$. rotunda on these specific ion channels and therefore, we put forward that exploration in this direction is warranted.

The inhibition of CAPs amplitudes by BREE was totally absent when the opioid receptors were non-specifically blocked, clearly indicating that BREE interact with opioid receptors on the membrane surface of nerve cells to exhibit analgesia. Early studies by Jurna and Grossmann (1977) reported naloxone-sensitive CAP inhibition in mammalian peripheral nerve fibers. It is a known fact that opioid receptors have an important role in the peripheral and central modulation of pain (Al-Hasani and Bruchas, 2011). Activation of opioid receptors cause a decrease in the conductance of voltage-gated $\mathrm{Ca}^{2+}$ channels or open rectifying $\mathrm{K}^{+}$channels (Stein, 2016). The reduced conduction of $\mathrm{Ca}^{2+}$ channels prevents the influx on $\mathrm{Ca}^{2+}$ into the neurons, thus leading to a decrease in neurotransmitter release at the nerve terminals disrupting the continuity of pain transmission. Activated opioid receptors prevent the opening of $\mathrm{K}^{+}$channels, causing $\mathrm{K}^{+}$ions to be retained inside the neurons (Luo et al., 2015). The failure of the neurons to depolarize prevents the propagation of action potential. Therefore, pain is not transmitted, achieving analgesia. In summary, we conclude that the current study demonstrated the pain relieving effect of BREE is due to the inhibition of CAPs via the activation of opioid receptors.

\section{0}

\section{Conclusion}

Taken together, the outcome shows that BREE has an inhibitory effect on nerve conduction, as it is able to decrease the CAPs amplitude whereby the effect is reversible. Further, we also report the involvement of opioid receptors in its inhibitory action on nerve conduction. This study is hoped to provide an in depth data on the pain relief effect of BREE, to be potentially used in therapies for pain management.

\section{Conflict of Interest}

The authors declare no conflict of interest. 


\section{Acknowledgements}

The authors thank the Faculty of Medicine and Health Sciences, Universiti Putra Malaysia, and the Physiology Laboratory for providing the necessary support for the study. This research was supported by Grant Putra (GP-IPM/2014/9433700) from Universiti Putra Malaysia,

\section{0}

\section{References}

Al-Hasani, R., \& Bruchas, M. R. (2011). Molecular mechanisms of opioid receptor-dependent signaling and behavior. The Journal of the American Society of Anesthesiologists, 115(6), 1363-1381.

Chahyadi, A., Hartati, R., Wirasutisna, K. R., \& Elfahmi. (2014). Boesenbergia pandurata roxb., an Indonesian medicinal plant: Phytochemistry, biological activity, plant biotechnology. Procedia Chemistry, 13, 13-37.

Chipman, P. H., Schachner, M., \& Rafuse, V. F. (2014). Presynaptic NCAM is required for motor neurons to functionally expand their peripheral field of innervation in partially denervated muscles. Journal of Neuroscience, 34(32), 10497-10510.

Chuakul, W., \& Boonpleng, A. (2003). Ethnomedical uses of Thai Zingiberaceous plant (1). Journal of Medicinal, 10(1), 33-39.

Colucci, V., Strichartz, G., Jolesz, F., Vykhodtseva, N., \& Hynynen, K. (2009). Focused ultrasound effects on nerve action potential in vitro. Ultrasound in Medicine \& Biology, 35(10), 1737-1747.

Eng-Chong, T., Yean-Kee, L., Chin-Fei, C., Choon-Han, H., Sher-Ming, W., Li-Ping, C. T., Gen-Teck, F., Khalid, N., Abd Rahman, N., \& Karsani, S. A. (2012). Boesenbergia rotunda: From ethnomedicine to drug discovery. Evidence-Based Complementary and Alternative Medicine, 2012.

Fry, C. H., \& Jabr, R. I. (2010). The action potential and nervous conduction. Surgery (Oxford), 28(2), 49-54.

Guang, H. M., \& Du, G. H. (2006). Protections of pinocembrin on brain mitochondria contribute to cognitive improvement in chronic cerebral hypoperfused rats. European Journal of Pharmacology, 542(1-3), 77-83.

Jurna, I., \& Grossmann, W. (1977). The effect of morphine on mammalian nerve fibres. European Journal of Pharmacology, 44(4), 339-348.

Katerere, D. R., Gray, A. I., Kennedy, A. R., Nash, R. J., \& Waigh, R. D. (2004). Cyclobutanes from combretum albopunctatum. Phytochemistry, 65, 433-438.

Katsuki, R., Fujita, T., Koga, A., Liu, T., Nakatsuka, T., Nakashima, M., \& Kumamoto, E. (2006). Tramadol, but not its major metabolite (mono-o-demethyl tramadol) depresses compound action potentials in frog sciatic nerves. British Journal of Pharmacology, 149(3), 319-327.

Kirana, C., Record, I. R., McIntosh, G. H., \& Jones, G. P. (2003). Screening for antitumor activity of 11 species of Indonesian zingiberaceae using human MCF-7 and HT-29 cancer cells. Pharmaceutical Biology, 41(4), 271-276.

Kurkin, V. A., Zapesochnaya, G. G., \& Braslavskii, V. B. (1990). Flavonoids in buds of Populus balsamifera. Khimiya. Prirodnykh Soedinenii, 2, 272-273.

Li, Z., Yang, J., Liu, J., Gong, C.-Y., Gan, J., Zhang, X., Luo, W.-J., \& Li, G.-h. (2010). Reversible conduction block in isolated toad sciatic nerve by emulsified isoflurane. Anesthesia \& Analgesia, 110(4), 1024-1029.

Luo, J., Feng, J., Liu, S., Walters, E. T., \& Hu, H. (2015). Molecular and cellular mechanisms that initiate pain and itch. Cellular and Molecular Life Sciences, 72(17), 3201-3223.

Mizuta, K., Fujita, T., Nakatsuka, T., \& Kumamoto, E. (2008). Inhibitory effects of opioids on compound action potentials in frog sciatic nerves and their chemical structures. Life Sciences, 83(5), 198-207.

Pandey, A. K., \& Deshpande, S. B. (2012). Bisphenol A depresses compound action potential of frog sciatic nerve in vitro involving Ca2+dependent mechanisms. Neuroscience Letters, 517(2), 128-132.

Riswan, S., \& Sangat-Roemantyo, H. (2002). Jamu as traditional medicine in Java, Indonesia. South Pacific Study, 23(1), 1-10.

Scholz, A. (2002). Mechanisms of (local) anaesthetics on voltage-gated sodium and other ion channels. British Journal of Anaesthesia, 89(1), 52-61.

Shi, L. L., Qiang, G. F., Gao, M., Zhang, H. A., Chen, B. N., Yu, X. Y., Xuan, Z. H., Wang, Q. Y., \& Du, G. H. (2011). Effect of pinocembrin on brain mitochondrial respiratory function. Yao Хue Xue Bao, 46(6), 642-649.

Shindo K, K. M., Kinoshita A, Kobayashi A, Koike Y. (2006). Analysis of antioxidant activities contained in the Boesenbergia pandurata Schult. Rhizome. Bioscience, Biotechnology, and Biochemistry, 70(9), 2281-2284.

Stein, C. (2016). Opioid receptors. Annual Review of Medicine, 67, 433-451.

Trakoontivakorn, G., Nakahara, K., Shinmoto, H., Takenaka, M., Onishi-Kameyama, M., Ono, H., Yoshida, M., Nagata, T., \& Tsushida, T. (2001). Structural analysis of a novel antimutagenic compound, 4-hydroxypanduratin A, and the antimutagenic activity of flavonoids in a Thai spice, fingerroot (Boesenbergia pandurata Schult.) against mutagenic heterocyclic amines. Journal of Agricultural and Food Chemistry, 49, 3046-3050.

Tremont-Lukats, I. W., Teixeira, G., \& Backonja, M. (2005). Systemic administration of local anesthetic agents to relieve neuropathic pain. The Cochrane Library.

Tuntiwachwuttikul, P., Pancharoen, O., Reutrakul, V., \& Byrne, L. T. (1984). (10 rs,20 sr,60 rs)-(2,6-dihydroxy-4- methoxy-phenyl)-[30 methyl-20 -(300-methylbut-200-enyl)- 60 -phenyl-cyclohex-30 -enyl] methanone (Panduratin A), a constituent of the red rhizomes of a variety of Boesenbergia pandurata. Australian Journal of Chemistry, 37, 1739-1745.

Win, N., Awale, S., Esumi, H., Tezuka, Y., \& Kadota, S. (2008). Panduratins D-I, novel secondary metabolites from rhizomes of Boesenbergia pandurata. Chemical \&Pharmaceutical Bulletin, 56, 491-496.

Winarti, L., \& Wantiyah, W. (2015). Examination of analgetics effects of extract Boesenbergia pandurata (Roxb.) schlechter to swiss furrow male mice. Traditional Medicine Journal, 16(1), 26-33.

Yao, L.-H., Yu, H.-M., Xiong, Q.-P., Sun, W., Xu, Y.-L., Meng, W., Li, Y.-P., Liu, X.-P., \& Yuan, C.-H. (2015). Cordycepin decreases compound action potential conduction of frog sciatic nerve in vitro involving Ca2. Neural Plasticity, 2015.

Youdim, K. A., Qaiser, M. Z., Bergley, D. J., RiceEvans, C. A., \& Abbott, N. J. (2004). Flavonoids permeability across an in situ model of the blood-brain barrier. Free Radical Biology and Medicine, 36, 592-604. 